\title{
Linguistic challenges faced by rural Tshivenda-speaking teachers when Grade 4 learners transition to English
}

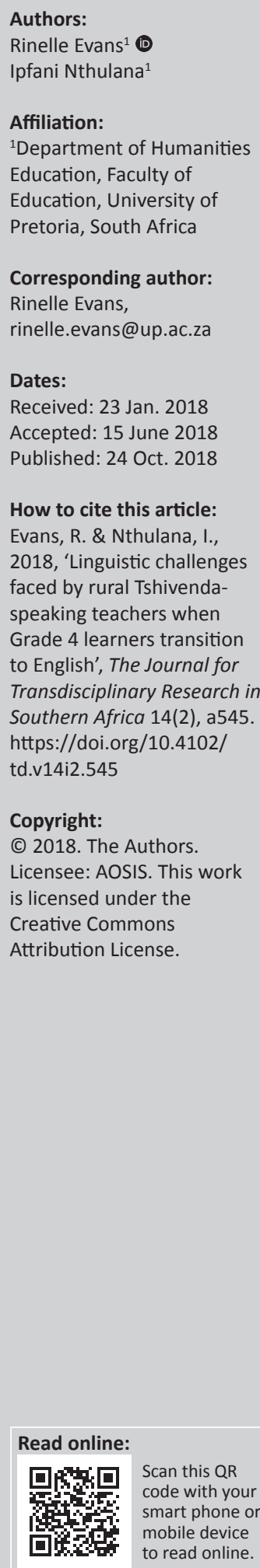

\begin{abstract}
The general complaint of teachers in rural monolingual communities is that teaching becomes problematic after learners are promoted to Grade 4 . While the transition to a next academic phase places new cognitive demands on the learners, they must also adjust to being taught in English after 3 years of mother tongue education. This qualitative case study was underpinned by Krashen's theory of second-language acquisition which emphasises the importance of exposure to and interaction in the target language. Six Grade 4 teachers who are mother tongue speakers of Tshivenda and two curriculum advisors participated in the study. Data were collected through individual interviews and classroom observations. Initially, it was assumed that the transition was problematic, because learners' English proficiency was inadequate, but teachers too struggled to impart academic content to Grade 4 learners and relied heavily on code switching. This strategy contributed to learners' understanding of content, but militated against any improvement in their English. The remoteness of this rural monolingual community implies a limited exposure to the target language, but ought not to be reckoned an excuse. Means to build teachers' linguistic confidence and improve their oral proficiency during initial teacher preparation as well as greater in-service support should ameliorate the transition for learners. A revision of the mother tongue Foundation Phase curriculum and monitored implementation is advisable.
\end{abstract}

\section{Introduction}

Many former colonies have grappled with decisions related to which language of instruction ought to be used at the inception of formal schooling, and perhaps none more so than South Africa. Since the dawn of democracy in 1994, various South African (SA) policies have worked towards establishing a citizenry based on democratic values, social justice and fundamental human rights - in short, a society that embraces a diversity of views and languages.

The SA Constitution (1996) promotes multilingualism and cultural diversity underpinned by respect for all languages, while acknowledging the maintenance of home languages. The $S A$ Schools Act (1996) allows for the medium of instruction to be the mother tongue in the Foundation Phase (Grade R to Grade 3), with a switch to English or Afrikaans as the language of learning and teaching (LOLT) from Grade 4 for those learners whose mother tongue is neither English nor Afrikaans (Department of Basic Education [DBE] 2011a; 2011b). In urban schools where the racial and linguistic composition is diverse, it has commonly been accepted that English will serve as a medium of instruction right from the first school day, as the range of learners attending is too great to isolate a single common home language to use as the LOLT (Alexander 2002; Bamgbose 2005; DBE 2010; Evans \& Cleghorn 2012; Heugh 2002; Pretorius 2014).

Teaching a young child using an unfamiliar language gives rise to many complex classroom encounters (Alexander 2002; Alexander \& Bloch 2004; Alidou et al. 2006; Evans \& Cleghorn 2012; Fleisch 2008; Heugh 2002; 2009; Pitman, Majhanovich \& Brock-Utne 2010; Wolff 2016). Learners in rural SA communities are largely taught in a monolingual context for the first 4 years of formal schooling, seemingly providing a solid conceptual foundation (DBE 2010). The advantages of mother tongue education are well documented. Rural learners are, however, apparently not linguistically better off, as both teachers and learners experience a unique problématique which will be illuminated in this article.

Drawing on interview and observational data, we attempt to answer why Tshivenda-speaking content teachers in the deep rural area of the Limpopo Province find that teaching becomes 
challenging after learners have been promoted to Grade 4 . We describe the various changes learners face when moving from Foundation Phase to Intermediate Phase. We also describe the linguistic challenges that the teachers face and how these are addressed in the instructional context. We dispel the belief that it is primarily the young learners who struggle after the abrupt transition from their mother tongue to English as the new LOLT. Furthermore, we draw attention to a hidden aspect of rural education in South Africa, that is, the lack of exposure to English that both teachers and learners have, but the assumption is that both role players are sufficiently proficient to guarantee a satisfying school experience.

\section{Situating the study within the literature}

Our conceptual framework guided the literature reviewed to present a synopsis of the research that has been conducted on transitioning from one phase to the next, and how rurality may exacerbate learning through a foreign language. We also allude to the SA language-in-education policy (1997) and its flawed implementation. In keeping with the tenets of qualitative inquiry, we have merged the literature review with contextual factors as will be discussed in the data analysis.

The concept transitioning suggests a discontinuation and a new beginning (Alidou 2003; Amest \& Rojas 2010) and bringing about a change in behaviour or routine (Giallo et al. 2010). It may be considered a rite of passage, a crossover to another stage, but also implies a process that is ongoing, requires adjustment and is accompanied by many expectations (Arnold et al. 2008). In our study, transitioning refers to an academic shift from the Foundation Phase to the Intermediate Phase. We forthwith offer an overview of the SA context.

After a mere 6-weeks' summer break, 10-year-old learners return in mid-January and, without any orientation, transitioned as Grade 4 learners into a new academic phase very dissimilar to their initial school experiences. Firstly, accustomed to having been taught all day by a single teacher, they now have multiple teachers - each with a unique instructional and management style, and each offering new but compartmentalised content every $40 \mathrm{~min}$. In many cases, the learners also move physically from class to class rather than remaining in a fixed, familiar venue for an entire day. Secondly, having mastered only simple learning tasks in the Foundation Phase, learners now experience a rich and demanding curriculum; the volume of work mushrooms, and content knowledge becomes diverse and must be applied in a complex manner. Thirdly, oral proficiency is no longer sufficient for responding to academic demands. Learners have already learnt to read in their mother tongue and are now supposedly ready to 'read for learning', that is, they need to demonstrate '... a growing reliance on literate practices for transmitting, acquiring and transforming knowledge' using these decoding skills (Pretorius 2014:53).
The foremost change for many SA learners as proposed by policy documents (DBE 2011a; Hirsch 2003; Holmarsdottir 2005; Pretorius 2014) is, however, from learning through the mother tongue to learning through the medium of English. In addition to the shift in how knowledge is accessed, the learning experience for rural learners associated with this study is compounded by the dramatic change in the LOLT. A high level of competency is anticipated by the end of Grade 3, as learners are expected to respond in English, constructing meaning from complex syntactic structures as manifest in written text - despite less than $4 \mathrm{~h}$ per week having been spent on learning English in the Foundation Phase (DBE 2011a; 2011b).

At the schools involved in this study, a major cognitive shift was required, as Tshivenda - the LOLT since starting school formally - does not share many characteristics with English and an entire new set of coding needs to be learnt and applied. Unlike English that has Germanic roots, Tshivenda belongs to the Bantu language family (a sub-category of the Niger-Congo family) and emerged as a distinct dialect in the 16th century, although speakers today consider themselves a marginalised language group (Webb \& Sure 2000). As a result of the genetic relationship that exists among Bantu languages, Tshivenda shares similar linguistic features, for example, specific noun classes, an open syllable structure and an extensive agreement system. It has vocabulary similar to Sesotho, but grammatical structures are closer to Chishona as spoken in Zimbabwe. Furthermore, Tshivenda is a tonal language and acoustic prominence is awarded to the penultimate syllable of the last word in a sentence. Tshivenda is an agglutinative code with a very complex morphology and its orthography makes extensive use of diacritic symbols for the representation of speech sounds foreign to English (Ammon 2006; Meshtri 2002; Van Wyk 1966). These salient features differ distinctly from English and, although not the focus of this study, may account for some of the challenges faced by learners.

Furthermore, Cummins $(1979 ; 2000)$ claims that it takes at least two years to acquire basic interpersonal communication skills (BICS) in an additional language, although perhaps less when there is more exposure to the target language, while it takes seven years to master cognitive academic language proficiency (CALP). Many Grade 4 learners thus face challenges in English, as they have barely mastered CALP in their home language, but are expected to cope with academic demands in a new medium of instruction.

Phatudi (2007) asserts that such an abrupt transition with so many changes not only affects academic performance, but also brings about disparity and reorganisation of the inner feelings and emotions of those that undergo it. This unsettledness is exacerbated by the fact that this linguistic transition is expressly made on behalf of the learners and possibly even parents without their being actively involved in the decision-making (Evans 2017; Evans \& Cleghorn 2012; Heugh et al. 2007). 
Finally, although in no way explored in this study, the Grade 4 slump needs mention as an internationally known phrase coined by Chall, Jacobs and Baldwin (1990). This baffling phenomenon occurs around the age of nine, just before SA learners would be transitioned transition to the Intermediate Phase. In terms of vocabulary, this academic slump relates to learners progressing from high-frequency words to more complex idiomatic structures. Being faced with text, which requires sophisticated decoding skills and a broad vocabulary, learners may be faced with 'a previously undetected lack of fluency and automaticity' (Goodwin 2011:88) and an overtaxed working memory (Torrance 1967). Chall et al.'s research (1990), moreover, found that the vocabulary of learners from low-income backgrounds was limited to basic words used in their immediate environment. By contrast, those learners whose environment exposed them to more variety and depth in terms of lived experiences had a richer vocabulary. A simple transposition of this premise to deep rural African contexts would not be invalid: the mother tongue would, no doubt, account for a richness of oral expression, while the English vocabulary would be very limited.

Turning attention now to rurality: we refrain from providing a blanket definition. Yet, in most contexts, this concept is generally defined in terms of low population density and remote geographic location, that is, isolation because of distance from modern infrastructure, facilities, services and technological connectivity. Lack of transport to the nearest towns implies high costs and infrequent contact with such destinations. Often these small settlements also subsist under harsh climatic conditions (Nthulana 2016; Rousseau 1995; Sher 1981). Rural regions are also defined in terms of socio-economic growth and sustainability, and tend to be among the poorest in a country, as those living there are generally deprived of job opportunities and thus cannot rely on a steady income. In the SA context, such areas are primarily inhabited by the elderly and minors (Balfour 2010; Stats SA 2011). The inequalities, produced by colonisation and apartheid, have further worsened the plight of such communities. Even post-apartheid policy frameworks, designed by middle-class professionals, have been insensitive to rural expressions and have favoured the urban elite (Chigbu 2013; Nelson Mandela Foundation \& Human Science Research Council 2005).

Rural communities, possibly owing to their isolation from mainstream culture, generally display a strong group cohesion and unique culture. Their close relationship with each other and nature is more than neighbourliness and has been described as Gemeinschaft (Tönnies 1963), suggesting personalised fellowship and 'a sharing of responsibilities, and a furthering of mutual good through familiarity and understanding' (Robinson 1990:37). These settlements in South Africa are particularly vulnerable, as traditional leaders control most aspects of life and supposedly represent their community's interests. Parents, too, are often marginalised and trapped, as their own schooling usually does not extend beyond primary level (Balfour 2010). Despite the apparent collective decision-making and reaching of consensus in rural communities, poorly educated parents are inclined to accept the opinions of community leaders and do not question policies even when not comprehended.

Teaching in rural contexts has its own challenges (Balfour 2010; Chigbu 2013; Heugh 2014; Robinson 1990; Sher 1981). Rural schools, although generally smaller in terms of learner size and with a relatively homogeneous learner profile, are often obliged to combine classes, serving learners across age groups. Learners travel long distances to reach schools, mostly on foot as transportation is non-existent, infrequent or expensive.

South Africans, living in deep rural areas, are generally monolingual, as their isolation also implies that they do not need to use even other regional languages, let alone the one widely associated with white speakers. Interaction with authentic speakers of English is very rare and seldom goes beyond an initial exchange of greetings. Overall, there are very few opportunities to practise communicating in English, implying inadequate English exposure for an entire community. However, caregivers, represented by the school governing body, also have the right to decide on the medium of instruction. As English is currently viewed as the language of power and prosperity (Evans \& Cleghorn 2010, 2012; Nomlomo 2010; Oliver \& Reschley 2007; Van der Walt \& Evans 2017), many of them insist on English despite the young children's lack of proficiency in this language.

Commonly for learners in our study, the only chance of hearing and using English happens at school where textbooks, learning support material and examination papers are prepared in English, presenting unfamiliar content in foreign words. Often these materials carry a strong Eurocentric, middle-class bias that emphasises the division between social literacy and the literacy required and acknowledged by the school (Bloch 2009; Chimbutane 2011; DBE 2010; Galabawa 2010; Heugh 2014; Pretorius 2014). More often too, the materials are shared and not permitted to be taken home. Aural English input is limited to hearing a non-native speaker with doubtful proficiency in the classroom. The only exposure that these rural teachers have to English is through the media. Yet, even these possibilities fail to allow for practising the target language, as paper and technology do not interact in an authentic, bidirectional way.

Our study was conducted in three government-funded primary schools situated in the Vhembe district - the epitome of rurality - approximately $90 \mathrm{~km}$ from the nearest town and $140 \mathrm{~km}$ from the Zimbabwean border. The Tshikondeni coal mine employs about 770 locals, while others in the community are subsistence farmers or traders of firewood and mopani worms - a rich source of protein seasonally abundant in this area. This site experiences very low rainfall, especially in winter. Electricity and limited 
solar power is available, but most families still prefer to prepare food using an open fire.

Most schools in the area have new classrooms, but owing to increased learner enrolment, the old ones are also still in use. Although water pipelines have been laid, they are usually dry and schools thus depend on boreholes and pit toilets for sanitation. Most learners travel more than $3 \mathrm{~km}$ on foot to get to school. In addition, they perform domestic chores after school, for example, collecting firewood from the forest, taking care of the herds until sunset, cutting grass for thatching a homestead or fetching water in $25 \mathrm{~L}$ drums transported on a wheelbarrow from some distance away. These routines are performed regardless of the weather and with little regard for the age of the child. Teachers in these areas reside in the local communities where interacting in Tshivenda only creates singularly monolingual spaces.

\section{Research design and method}

This case study was designed as a qualitative research project underpinned by Krashen's theory (1982) of second-language acquisition which stresses the significance of oral interaction in enhancing acquisition and fluency. Data were collected by means of interviews and non-participant classroom observation.

The sites and possible teacher participants were assigned to us by the district office based on our selection criteria for purposive sampling which required more than three years' teaching experience in a rural environment, a minimum of three years' experience teaching Grade 4 learners and having a relevant professional qualification. The teachers should also have attended at least $70 \%$ of the professional development programmes on offer.

Six teachers aged between 35 and 55 years, three males and three females, agreed to participate in this study. All teachers were mother tongue speakers of Tshivenda, spoke multiple languages, but considered their English proficiency mediocre, as they did not use it outside the classroom. Only one stayed within walking distance of the school, while the others travelled between $20 \mathrm{~km}$ and $30 \mathrm{~km}$ daily to reach their workplace. Although they complained about too many changes in the curriculum, overcrowded classrooms, lack of textbooks and not earning enough, participants all seemed passionate about teaching and enjoyed being with their learners. Two Intermediate Phase curriculum advisors (CAs) (also identified by the circuit manager) were interviewed to establish whether they were aware of any challenges that Grade 4 teachers faced and to find out what initiatives they took to support teachers.

Data collection commenced once ethical clearance had been obtained from the relevant authorities and participants. Interview questions were first piloted with rural teachers elsewhere in Limpopo in order to establish whether they would elicit the data we required. Thirty-five predetermined questions were arranged in five sections. Six questions sought to ascertain biographical information, eight focussed on teaching experience, while seven dealt with teaching methodology. The remaining questions gleaned data related to classroom interactions and the support channels available. We conducted a single, in-depth, face-to-face interview with each of the participants in the second term of the school year. The 60-min teacher interview was site-based, semistructured and audio-recorded. The questions were posed in English, but all participants chose to respond in Tshivenda, as they could express themselves better. A similar process was followed when interviewing the CAs, although they only had 18 questions and were interviewed for $45 \mathrm{~min}$. Participants' anonymity was protected by giving them pseudonyms. Interviews were transcribed verbatim and translated by the co-author, and then combed for themes in several iterations. The interview data, sets per participant, presented in the main study as a narrative, were tabulated for ease of comparison and later triangulated with the observational data.

The primary researcher conducted non-participant observations of authentic lessons in situ presented by three participating teachers from the same school. This verified data, obtained by class visits, helped us to fully comprehend the complexities of teaching in a rural classroom and highlighted discrepancies between what the participants said they did and the reality witnessed. Behavioural patterns that teachers were unaware of were also revealed. Distance affected visits to the other two research sites.

Mindful of the 'Hawthorne effect', that is, the possibility of both learners and teachers changing their behaviour in the researcher's presence (Kumar 2011:141), we effectively managed this through a pre-observation visit to establish rapport with teachers and to explain to the learners the planned chain of events. Learners were also familiarised with the equipment and the assistant who would be helping with the recordings. Both a phone for audio recordings and a video camera were used in case technical errors arose.

An observation frequency schedule was designed to focus on how the teacher conducted the lessons and how the learners responded. There was a specific focus on the language used in the various exchanges. Each observation lasted approximately $2 \mathrm{~h}$, permitting the primary researcher to observe teachers' strategies when introducing a lesson and explaining the new content as well as gauge the learners' reactions and level of understanding.

\section{Data presentation}

Drawing on the data sets, we now offer a consolidated account of five key patterns pertinent to the intersecting of language proficiency for academic purposes and rural education. 


\section{Pattern \#1: Teachers' inadequate proficiency in the language of learning and teaching}

The six teacher participants self-identified strongly with their deep rural monolingual Tshivenda-speaking community. Although multilingual in terms of other SA languages, they admitted that they had very limited exposure to English as a language of communication. They claimed to have only really encountered it while studying at the local teachers' training college many years ago or at university where English had been used as a medium of instruction. They had never had an opportunity to socialise in English, because the majority of their fellow students had also been Tshivenda speakers. One of the teachers had completed her academic qualifications at secondary and tertiary level via correspondence and thus only had exposure to English in written form through her study material and examination papers.

None of the teachers used English outside the classroom. Some participants lacked confidence when speaking English and felt embarrassed when making a mistake. Mukondeleli admitted her inadequacy unashamedly:

Truly speaking I feel that I cannot speak it (English) because I cannot say exactly where I ever stood in front of anyone and speak in English ... when teaching them through English I could see that my English is not much perfect as compared to some children that I teach. But unlike when I am reading, I will understand but it is so hard to say in English what I have been reading. (Participant 2 , female, teaches Maths)

It appeared that the only time that these teachers used any English was when they taught and, even then, it was limited to giving basic instructions and lean explanations, while much code switching also took place.

Four teachers rated their English ability as five out of ten; another felt that some learners spoke English better than herself, referring to those whose parents had taken them to private preschools, while only Maswoi rated himself six out of ten. When asked how well teachers speak English, one CA made a vague statement that 'some are good and some are not good'. The other was also reluctant to express an opinion about teachers' linguistic prowess in English, because 'they may report you to their unions'.

\section{Pattern \#2: Learners' linguistic underpreparedness}

Learners in our study generally only speak Tshivenda at home and the classroom is the only context in which they encounter English. A CA explained this as follows: '... the only exposure that I know of is that of a television but eh ... a television does not communicate. It's only characters [who don't talk to the viewer]'. Advisors justified their detached stance by claiming that learners should use English outside the classroom, but admitted that 'this is a rural area where they will never meet a white person'. Curriculum advisors also recognised that learners transitioned with less than an elementary knowledge of English, implying a seriously underdeveloped CALP, but did not question the abrupt switch to a new LOLT that impacted learning. The introduction of English in earlier grades by means of simple songs and chanting without purposeful language development was not questioned either. They also indicated that more English should be introduced gradually in the Foundation Phase, but without suggesting how:

Instead of going on with the Grade 4 curriculum, they must first teach the elementary part of the curriculum (a e i o u), that is, sounds and the alphabet, to help learners cope. (Participant 1 , male, teaches Maths)

Furthermore, the CAs did not elaborate on why teachers complained about following the official curriculum and assessment policy, but believed that code switching helped learners understand the content thus endorsing the continued use of Tshivenda after transitioning. The CAs also paid lip service to the support they were expected to offer and blamed the remote location for the learners' struggle.

Classroom observations confirmed that learners did not understand when instructed in English and teachers reverted to explanations in Tshivenda. As learners had a limited vocabulary, they could not comfortably provide wellconstructed answers to questions and battled to give logical responses, but could do so in their mother tongue. When asked to give their answers in English, a few learners responded immediately. However, when permitted to answer in Tshivenda, almost the whole class would raise their hands. There were also learners who could not read any English meaningfully. Learners' self-esteem faded visibly whenever they struggled to express themselves. They kept quiet when called upon in English, but responded eagerly once teachers rephrased the same question in Tshivenda. Five of the six participants also taught in upper grades and averred that most of the older learners coped better with the demands of English even though they did not meet them fully. Three teachers stated that they referred learners who were not coping in Grade 4 back to a lower grade teacher so that they could be helped ('We revert to a FP teacher to minimise the problem'). It was unclear whether this was for support in linguistic or academic skills and we pondered why an Intermediate Phase teacher might not be better equipped to solve such problems.

\section{Pattern \#3: Code switching as a means of coping in class}

Teachers endeavour to address their learners' struggle to understand new content by code switching between English and Tshivenda. Participant teachers spoke about 'translating' and 'interpreting' and were not aware that this behaviour had a linguistic label nor that it was a conventional and accepted strategy.

Official documents permit code switching (DBE 2011a), but the teachers expressed misguided guilt doing so as they believed that they were breaching policy and prescribed methodology. As claimed by a participant: 'We know we are 
supposed to teach them in English but we are forced by circumstances to do so [code switch] because they [learners] must understand' (Participant 5, female, teaches Maths).

Participant teachers had no knowledge of implementing code switching strategically and responsibly (Van der Walt 2009). Participants merely repeated whatever they had said in English in Tshivenda again. They intuitively knew that doing so would build up learners' confidence and understanding by bridging the conceptual gap:

We use both because when you start speaking in English you will see when children are unable to understand and is then that you will be able to explain in Tshivenda that they will understand and when they have understood it then you go back to English. (Participant 1, male, teaches Maths)

This echoes what Brock-Utne et al. (2010:84) experienced in Tanzania where teachers complained that if they used English throughout a lesson, it was like 'teaching dead stones'. All participants, however, agreed that code switching was timeconsuming 'because you have to go back to Tshivenda and it means one thing will be taught twice' and it thus 'made lessons become slower'.

Observation and interview data suggested that, at the commencement of a lesson, the phatic communication was conducted in English, but that explanations of content as well as behaviour management were executed in Tshivenda and, probably to salve feelings of guilt or for the sake of the observer, often repeated again in English. The relevance of alternating languages in this order was not clear, but presumably it was an attempt to adhere to the LOLT policy.

Both CAs seemed unaware of the extent to which teachers code switched, but felt that it was justified to translate the instructions for learners whenever they were given a formal assessment:

Because they don't understand English, they should be helped whenever they are given a formal assessment; teachers must first read the instructions and interpret into the mother tongue to make them understand. (Participant 1A, male, 5 years experience)

None of the participants admitted to using Tshivenda because they were more comfortable teaching in this language. Their lack of linguistic confidence in English, however, manifested in that they preferred to conduct their interviews in their mother tongue.

\section{Pattern \#4: Perceptions related to English as a language of instruction}

Despite participants' inability to adequately engage with content exposition in English, they still considered English an appropriate medium of instruction and were positive about the move from Tshivenda to English in Grade 4. All six teachers regarded English as important, because it is spoken internationally and that offers many opportunities, for instance when learners travel. Maseo felt 'I want the children to know other languages in today's world', supporting Mutshinya's opinion that being taught in English 'is helpful when learners are furthering their studies, they won't find it difficult'.

When asked whether they would prefer teaching in Tshivenda exclusively if permitted, two opposing views were evident. Some teachers felt that concepts in mathematics and science could not be explained well in English: 'If the learner knows fractions in Tshivenda, it will be easy for the learner to know them in English', while others felt 'it will be difficult because some [concepts] do not have names in Tshivenda' and 'There is little Maths vocabulary in Tshivenda language' or as Mutshinya declared:

Ha! Can it work? What will we call some of the things? This will be laughable during the first time! Some of the words we don't know them in Tshivenda. (Participant 6, male, teaches English)

Makhadzi believed that teaching in English '... is also helpful to us as teachers because we will also be practising to speak English'. Participants felt that despite learners' struggle to understand when taught in English, they were positive about the language and showed an interest in learning it.

When asked what concerns they had about English as LOLT, CAs focussed with false logic on the learners as the problem, stating that 'learners do not come with adequate elementary knowledge of English because educators are forced to teach in Grade 3 in the mother tongue so that these learners understand'.

\section{Pattern \#5: Perceived lack of support from district officials}

Teacher participants felt that not enough was being performed by 'the government' to prepare both teachers and learners for transitioning in the medium of instruction. Curriculum advisors agreed that this was a challenge, especially for rural teachers and learners. Although the CAs offered some help in the form of workshops, it was insufficient, as Maseo declares: 'No, it is not useful! Things that we should be taught in 3 years we are taught in two days.' Participants attended workshops on how to teach particular content subjects, but were emphatic about receiving no help from the department on how to teach through the medium of English, let alone how to improve their classroom English (Willis 1985).

The following caustic remark suggests that - rather than the cooperative and supportive rapport which ought to exist among CAs and teachers - there was a strained power-based relationship: '... they become more advanced in salary; they also pass you by the road driving those big cars. The way they change these curriculums, they don't give us time.'

Teachers voiced their complaints, but felt that they were not heard. Teachers termed CAs 'fault finders' and 'witch hunters', while the CAs experienced a decided lack of trust on the part of the teachers. One advisor considered the 
teachers in his district as equals, while the other person claimed that 'The problem is of attitudes, and those who will be acting on what their unions are saying and even misinterpret what their unions have said'. Both government officials made many excuses for not hosting more professional development opportunities, stating that the teachers 'get learning support materials and departmental workbooks and their own teaching plan to guide them on what to teach each week'. This they considered sufficient and had no plans to initiate any special programmes to support language transitioning or further development of English. The following remark is an indictment in terms of shirking responsibility: 'Due to the fact that XXX is far, and I am just assisting because there is a shortage. I do not often go there but I try...'

\section{Discussion}

Although the adult participants in this study unashamedly blamed the learners' lack of English for the linguistic challenges teachers faced with Grade 4 learners, the findings overwhelmingly suggest that it is the teachers 'inadequate English which results in complex classroom encounters' (Evans \& Cleghorn 2012). As the LOLT is the means by which knowledge is imparted and the intellectual potential of learners developed, such a language should be understood and used comfortably by both teachers and learners. The linguistic transition from Grade 3 to 4 implies that learners at this stage ought to have at least sufficient aural skills in English to understand simple content exposition. Teachers should likewise be sufficiently fluent in the LOLT and have the necessary subject jargon and classroom English to confidently and effectively explain concepts and manage the learning event. It is understandable that Grade 4 learners may still be acquiring the LOLT, but the expectation is that teachers would be more capable of leading in English at this level.

Code switching minimises the language barrier in the classroom, but overt linguistic inadequacies in the LOLT cause 'confusion, frustration or discomfort' (Evans \& Cleghorn 2012:78). Jegede (2012:43) suggests that teachers code switch as a means to cope with the challenges they face when using an unfamiliar language as a medium of instruction, supporting our notion that the Tshivendaspeaking teachers did so primarily because of their own inadequate proficiency. This dependence on code switching as the sole strategy to support learners, may improve understanding of content, but not English proficiency. Pollard (2002) again discourages code switching, as it tends to be detrimental to the development of both languages. Learners may also not heed English explanations, as they know that the entire lesson will be repeated in Tshivenda. This practice further limits rural learners' exposure to English (Duran 1994; Nel \& Muller 2010; Oyeomoni 2006; Pollard 2002). A lengthier and less obtrusive means of observation may have allowed us to gauge just how much English was, in fact, being used.
As the school is the only site at which rural learners encounter English, their teachers serve as role models. One of the tenets of Krashen's language acquisition theory (1982) is that teachers ought to offer comprehensible input in the target language at a slightly higher level than the learners would be able to produce. An environment, rich in second-language input, increases exposure, but in our study, the opportunity for the school to serve as a place to practise English for both teachers and learners was never fully utilised. This was unusual, especially as English was afforded high status being perceived as the key to fulfilling adult aspirations for the younger generation.

The rural and monolingual setting of this remote community has been used as an excuse for infrequent exposure to English. Although rural parents cannot support learners as they might in urban areas with social encounters in the LOLT, personal tutors and broad exposure to technology through which to access content and English, rural learners do have the ability to acquire BICS through sufficient exposure to English. Yet, the professionals responsible for the education of the Grade 4 learners are inert about taking responsibility for the level of readiness and seem to shift the blame. Although they acknowledged limitations in their own oral expression, participants did not question how to improve their own English proficiency with specific reference to the classroom discourse required to scaffold tasks and foster learning (Alexander 2008; Probyn 2001, 2009; Uys et al. 2007; Walsh 2013). Learners' underpreparedness could be improved by more frequent listening and speaking tasks (Arnold et al. 2008).

Our findings further point to a disjuncture in terms of policy implementation and the provision of professional interventions. Rural teachers feel hampered by an 'us-them' relationship with CAs on whom they rely for pedagogical support. Curriculum advisors blamed the remoteness of the school communities for the teachers' and learners' poor proficiency and displayed an exculpatory attitude towards their role in improving teachers' ability to use the LOLT effectively. Officials also feared retaliation from unions and their glib opinions reveal a lack of insight into what language proficiency entails - let alone how to develop proficiency in an LOLT. One wonders about their own English proficiency as well as their ability to identify which aspects of instructional communication and classroom English required attention. Or was their command of English being used to strengthen the power dynamics?

Adult participants knew that not enough was being done, but seemed not to know how to address the key problem: the vicious circle of poor English input by teachers resulting in poor output by learners.

\section{Significance and implications}

Our findings contribute accumulatively to the broader narrative about rural education and the systemic ills that do not acknowledge the challenges and consequences of insufficient linguistic prowess for both teachers and learners. 
Although small scale and localised, this study has drawn attention to the linguistic predicament that rural communities experience when teachers are required to teach through the medium of English when neither they nor their learners have sound mastery of it (Evans \& Cleghorn 2010, 2012; Mohanty et al. 2009; Moyo, Beukes \& van Rensburg 2009; Murali 2009). It also highlights the imperative for teachers to grasp the role they play in learners' language development by ensuring increased quality exposure to the target language.

Implications arising from this study relate to national policymakers and local policy implementers as well as institutions responsible for teacher education, making concerted efforts to provide official support to both teachers and learners to prepare them for the shift to a new medium of instruction in Grade 4. The education ministry ought to display the necessary political will to design and implement measures that will support 21st century teachers to use English with ease, especially those teaching in rural areas. Large-scale application is required, as it is not only rural teachers (and learners) who require language support. Language development is a complex and longitudinal process requiring appropriate input and practice. All role players involved in education may need to be re-skilled in this respect.

Policymakers also need to reflect on a more gradual switch to English-only with greater and needs-driven exposure to the LOLT in the first years of schooling. Curriculum planners ought to revise the scope, content and means of teaching English in the Foundation Phase, emphasising goal-oriented vocabulary extension and introducing English phonics in a culturally appropriate manner. Currently, periods assigned for learning English are limited and lean. Increasing liaison between teachers of the different phases could also alleviate overall transitional challenges. School leadership ought to consider induction sessions during which official policy and procedures are discussed. This might prompt teachers to reflect on their own classroom practices and responsibilities should they have a close knowledge of policy documents.

The current scope of subject methodology training at institutions of higher learning is insufficient, while professional development initiatives, offered by the education ministry, seem unable to minimise teachers' challenges. Teacher education programmes need to include practical means of dramatically improving teachers' inadequate command of the LOLT prior to entering the classroom as a qualified teacher. The reintroduction of a standardised form of assessment to ensure adequate proficiency in at least two official languages would serve to ensure that instructional dissonance is limited (Evans \& Cleghorn 2010, 2012; Moyo et al. 2009; Nel \& Muller 2010). Teachers also require a solid understanding of language development in the first and additional languages as well as knowing how to adapt to rural education, as it differs from that in better resourced schools.

\section{Conclusion}

Rural teachers and learners still have a long, dusty road to run towards improving their level of English in order to alleviate the linguistic and transitional stress in Grade 4. Yet, their geographical isolation should not debar them from acquiring the LOLT adequately to ensure successful academic progress. In view of the many changes that these learners are exposed to when moving to Grade 4 - in particular, the linguistic demands they and their teachers face - they are in urgent need of governmental intervention to master what one participant accurately called 'this language [English] that came by ship'.

\section{Acknowledgements Competing interests}

The authors declare that they have no financial or personal relationships which may have inappropriately influenced them in writing this article.

\section{Authors' contributions}

I.N. was a master's student and contributed $15 \%$ of the article. R.E. was the supervisor of I.N. and contributed 85\% of the article. R.E. conceptualised, wrote and edited the final manuscript using findings from I.N.'s dissertation.

\section{References}

Alexander, N., 2002, 'Linguistic rights, language planning and democracy in postapartheid South Africa', in S. Baker (ed.), Language policy: Lessons from global models, pp. 116-129, Monterey Institute of International Studies, Monterey, CA.

Alexander, N. \& Bloch, C., 2004, 'Feeling at home with literacy in the mother tongue', paper presented at the IBBY Conference, September, Cape Town.

Alexander, R.J., 2008, Towards dialogic teaching: Rethinking classroom talk, 4th edn., Dialogos, York.

Alidou, H., 2003, 'Medium of instruction in post-colonial Africa', in J.W. Tollefson \& A. Tsui (eds.), Medium of instruction policies: Which agenda? Whose agenda? pp. 195-214, Lawrence Erlbaum Associates, Mahwah, NJ.

Alidou, H., Aliou, H., Brock-Utne, B., Diallo, Y.S., Heugh, K. \& Wolff, H.E. (eds.), 2006 Optimizing learning and education in Africa-The language factor: A stock-taking research on mother tongue and bilingual education in Sub-Saharan Africa, Association for the Development of Education in Africa (ADEA) and UNESCO Association for the Development of
Institute for Lifelong Learning, Paris.

Amest, P. \& Rojas, V., 2010, Change and opportunity: The transition from primary to secondary schools in rural and urban Peru, Department of International Development, Oxford, UK.

Ammon, U., 2006, Sociolinguistics: An international handbook of the science of language and society, Walter de Gruyter, Berlin.

Arnold, C., Bartlett, K., Gowani, S. \& Shallwani, S., 2008, 'Transition to school: Reflections on readiness', Journal of Developmental Processes 3(2), 26-38.

Balfour, R., 2010, 'Rural education and rural realities: The politics and possibilities of rural research in Southern Africa', Perspectives in Education 29(2), i-ix.

Bamgbose, A., 2005, 'Mother tongue education: Lessons from the Yoruba experience', in B. Brock-Utne \& R.K. Hopson (eds.), Languages of instruction for African
emancipation - Focus on post-colonial contexts and considerations, pp. 231-257, emancipation - Focus on post-colon
Mkuki na Nyota, Dar es Salaam.

Bloch, G., 2009, The toxic mix: What's wrong with South Africa's schools and how to fix it, Tafelberg, Cape Town.

Brock-Utne, B., Desai, Z., Qorro, M.A.S. \& Pitman, A. (eds.), 2010, Language of instruction in Tanzania and South Africa - Highlights from a project, Sense Publishers, Rotterdam.

Chall, J.S., Jacobs, V.A. \& Baldwin, L.E., 1990, The reading crisis: Why poor children fall behind, Harvard University Press, Cambridge, MA.

Chigbu, U.E., 2013, 'Rurality as a choice: Towards ruralising rural areas in sub-Saharan African countries', Development Southern Africa 30(6), 812-825. https://doi.org/ 10.1080/0376835X.2013.859067

Chimbutane, F., 2011, Rethinking bilingual education in postcolonial contexts, Multilingual Matters, Bristol, UK. 
Cummins, J., 1979, Cognitive/academic language proficiency, linguistic interdependence, the optimum age question and some other matters, Working Papers on Bilingualism, No. 19, Bilingual Education Project, The Ontario Institute for Studies in Education, No. 19, Bilingual Education Project, The Ontario Inst
Toronto, pp. 121-129, ERIC document ED 184334.

Cummins, J., 2000, Language, power and pedagogy: Bilingual children in the crossfire, Multilingual Matters, Clevedon.

Department of Basic Education (DBE), 1997, Language-in-education policy, Republic of South Africa, Government Printers, Pretoria.

Department of Basic Education (DBE), 2010, The status of the language of learning and teaching in South African public schools, Republic of South Africa, Government Printers, Pretoria.

Department of Basic Education (DBE), 2011a, Curriculum and Assessment Policy Statement (CAPS) intermediate phase, Republic of South Africa, Government Printers, Pretoria.

Department of Basic Education (DBE), 2011b, Programme and promotion requirements, Republic of South Africa, Government Printers, Pretoria.

Duran, L., 1994, 'Towards a better understanding of code switching and inter-language in bilingualism. Implications for bilingual instructions', Journal of Educational Issues of Language Minority Students 14, 69-88.

Evans, R., 2017, 'Koesister op 'n Royal Albert piering: 'n kritiese nabetragting van 'n nie-moedertaal onderwyservaring', Tydskrif vir Geesteswetenskappe/Journal of Humanities 57(3), 1-13.

Evans, R. \& Cleghorn, A., 2010, “'Look at the balloon blow up!”: Student teacher-talk in linguistically diverse South African Foundation Phase classrooms', Southern African Linguistics and Applied Language Studies 28(2), 123-133.

Evans, R. \& Cleghorn, A., 2012, Complex language encounters - A South African perspective, Sense Publishers, Rotterdam.

Fleisch, B., 2008, Primary education in crisis: Why South African school children underachieve in reading and mathematics, Juta, Pretoria.

Galabawa, J., 2010, 'Salient policy issues in the choice of language of instruction in Tanzania', in B. Brock-Utne, Z. Desai, M.A.S. Qorro \& A. Pitman (eds.), Language of instruction in Tanzania and South Africa - Highlights from a project, pp. 99-111 Sense Publishers, Rotterdam.

Giallo, R., Treyvaud, K., Matthews, J. \& Kienhuis, M., 2010, 'Making the transition to primary school: An evaluation of a transition program for parents', Australian Journal of Educational and Developmental Psychology 10, 1-17.

Goodwin, B., 2011, 'Research says ... don't wait until the 4th grade to address the Slump', Educational Leadership 68(2), 88-91.

Heugh, K., 2002, 'Teacher education issues: Implementation of a new curriculum and language in education policy', in N. Alexander (ed.), Mother tonguebased bilingual education in South Africa: The dynamics of implementation pp. 137-158, Multilingualism Network \& PRAESA, Cape Town.

Heugh, K., 2009, 'Contesting the monolingual practices of a bilingual to multilingual policy', English Teaching: Practice and Critique 8(2).

Heugh, K., 2014, 'Shades, voice and mobility: Afar pastoralist and Rift Valley communities (re)interpreting literacy and linguistic practices', Multilingual Margins: A Journal of Multilingualism from the Periphery 1(1), 16-39. https://doi. org/10.1057/9781137309860.0012

Heugh, K., Benson, C., Bogale, B., Alemu, M. \& Yohannes, G., 2007, Final report on medium of instruction in primary schools in Ethiopia, Ethiopian Ministry of Education, Addis Abba.

Hirsch, E.D., 2003, 'Reading comprehension requires knowledge of words and the world', American Educator 27(1), 10-13, 16-22, 28-29, 48.

Holmarsdottir, H.B., 2005, 'From policy to practice: A study of the implementation of the language-in-education policy (LiEP) in three South African primary schools', $\mathrm{PhD}$ dissertation, University of Oslo.

Jegede, O.O., 2012, 'Roles of code switching in multilingual public primary schools in Ile-Ife, Nigeria', American Journal of Linguistics 1(3), 40-46.

Krashen, S.D., 1982, Principles and practice in second language acquisition, University of Southern California: Pergamum Press Inc., Oxford.

Kumar, R., 2011, Research methodology: A step by step guide for beginners, Sage, London.

Meshtri, R. (ed.), 2002, Language in South Africa, Cambridge University Press, Cambridge.

Mohanty, A., Panda, M., Phillipson, R. \& Skutnabb-Kangas, T. (eds.), 2009, Multilingual education for social justice: Globalising the local, Multilingual Matters, Bristol, UK.

Moyo, J., Beukes, A. \& Van Rensburg, W., 2009, 'Teaching and learning English as a home language in a pre-dominantly non-native English classroom: A study from KwaZulu-Natal', Journal for Language Teaching 44(2), 23-38.

Murali, M., 2009, 'Teaching English as a second language in India - A review', The Modern Journal of Applied Linguistics 1(1), 2-10.
Nel, I. \& Muller, S., 2010, 'The impact of teachers' limited English proficiency on English second language learners in South Africa', South Africa Journal of Education 30, 635-650. https://doi.org/10.15700/saje.v30n4a393

Nelson Mandela Foundation \& Human Science Research Council, 2005, Emerging voices: A report on education in South African rural communities, Education Policy Consortium, HSRC Press, Pretoria.

Nomlomo, V., 2010, 'Parents' choice of the medium of instruction in Science: A case study of one primary school in the Western Cape, South Africa', in B. Brock-Utne, S. Desai, M.A.S. Qorro \& A. Pitman (eds.), Language of instruction in Tanzania and South Africa: Highlights from a project, pp. 189-206, Sense Publishers, Rotterdam.

Nthulana, I., 2016, 'Challenges faced by rural Tshivenda-speaking teachers when instructing Grade 4 learners in English', Unpublished Masters dissertation, University of Pretoria.

Oliver, M.R. \& Reschly, D.J., 2007, Effective classroom management: Teacher representation and professional development, National Comprehensive Centre for Teacher Quality, Washington, DC, viewed 12 January 2018, from https://files. eric.ed.gov/fulltext/ED543769.pdf

Oyeomoni, M.O., 2006, 'Code switching and code mixing style of language use in childhood in Yoruba Speech Community', Nordic Journal of African Studies 15(1), 90-99.

Phatudi, N.C., 2007, 'A study of transition from pre-school and home contexts to Grade 1 in a developing country', Unpublished PhD thesis, University of Pretoria.

Pitman, A., Majhanovich, S. \& Brock-Utne, B., 2010, 'English as language of instruction in Africa', in B. Brock-Utne, Z. Desai, M. A.S. Qorro \& A. Pitman (eds.), Language of instruction in Tanzania and South Africa - Highlights from a project, pp. 1-10, Sense Publishers, Rotterdam.

Pollard, S., 2002, The benefits of code switching with a bilingual education program, Honours Project, Paper 2, viewed 12 January 2018, from http://digitalcommons. iwu.edu/hispstu_honproj/2http://digitalcommons

Pretorius, E.J., 2014, 'Supporting transition or playing catch-up in Grade 4? Implications for standards in education and training', Perspectives in Education 32(1), 51-76.

Probyn, M., 2001, 'Teachers' voices: Teachers' reflections on learning and teaching through the medium of English as an additional language in South Africa', International Journal of Bilingual Education and Bilingualism 4(4), 249-266. https://doi.org/10.1080/13670050108667731

Probyn, M., 2009, "'Smuggling the vernacular into the classroom": Conflicts and tensions in classroom code switching in township/rural schools in South Africa', International Journal of Bilingual Education and Bilingualism 12(2), 123-136. https://doi.org/10.1080/13670050802153137

Republic of South Africa, 1996, Constitution of South Africa, Government Printer, Pretoria.

Republic of South Africa, 1996, South African Schools Act of 1996, Government Printer, Pretoria.

Robinson, G.M., 1990, Conflict and change in the countryside, Belhaven Press, London.

Rousseau, N., 1995, 'What is rurality?', in J. Cox (ed.), Rural general practice in the United Kingdom, pp. 1-4, Occasional Papers, Royal College of General Practitioners. London.

Sher, J.P. (ed.), 1981, Rural education in urbanised nations: Issues and innovations, Westview Press, Boulder, CO.

Statistics South Africa, 2011, Census 2011 Census in brief, viewed 14 January 2018 , from http://www.statssa.gov.za/census/census 2011/census products/Census 2011_Census_in_brief.pdf

Tönnies, F., 1963, Community and society, Harper and Row, New York.

Torrance, P., 1967, Understanding the fourth grade slump in creative thinking, US Office of Education, Washington, DC.

Uys, M., Van der Walt, J., Van den Berg, R. \& Botha, S., 2007, 'English medium of instruction: A situation analysis', South African Journal of Education 27(1), 69-82.

Van der Walt, C., 2009, 'The functions of code switching in English language learning classes', Per Linguam 25(1), 30-43.

Van der Walt, C. \& Evans, R., 2017, 'Is English the lingua franca of South Africa?', in J. Jenkins, M.J. Dewey \& W. Baker (eds.), The Routledge handbook of English as a Lingua Franca, pp. 186-198, Routledge, London.

Van Wyk, E.S., 1966, Die Bantoetale - 'n beknopte algemene oorsig, J.L. Van Schaik, Pretoria.

Walsh, S., 2013, Classroom discourse and teacher development, Edinburgh University Press, Edinburgh.

Webb, V. \& Sure, K., (eds.), 2000, African voices - An introduction to the languages and linguistics of Africa, Oxford University Press, Oxford.

Willis, J., 1985, Teaching English through English: A course in classroom language and techniques, Longman Handbooks for Language Teachers Series, Longman ELT, London.

Wolff, H.E., 2016, Language and development in Africa: Perceptions, ideologies and challenges, Cambridge University Press, Cambridge. 